Article

\title{
Hierarchically porous S-scheme CdS/UiO-66 photocatalyst for efficient 4-nitroaniline reduction
}

\author{
Jinxin Wei a,b, Yawen Chen a,b, Hongyang Zhang a,b, Zanyong Zhuang a,b,*, Yan Yu a,b,\# \\ a College of Materials Science and Engineering, Fuzhou University, New Campus, Fuzhou 350108, Fujian, China \\ b Key Laboratory of Eco-Materials Advanced Technology, Fuzhou University, Fuzhou 350108, Fujian, China
}

\section{A R T I C L E I N F O}

\section{Article history:}

Received 11 March 2020

Accepted 25 April 2020

Published 5 January 2021

\section{Keywords:}

Pore-size Effect

Nanoconfinement

Hierarchically porous MOFs

NPs/MOFs

Nanocage

\begin{abstract}
A B S T R A C T
Unveiling the pore-size performance of metal organic frameworks (MOFs) is imperative for controllable design of sophisticated catalysts. Herein, UiO-66 with distinct macropores and mesopores were intentionally created and served as substrates to create advanced CdS/UiO-66 catalysts. The pore size impacted the spatial distribution of CdS nanoparticles (NPs): CdS tended to deposit on the external surface of mesoporous UiO-66, but spontaneously penetrated into the large cavity of macroporous UiO-66 nanocage. Normalized to unit amount of CdS, the photocatalytic reaction constant of macroporous CdS/UiO-66 over 4-nitroaniline reduction was $\sim 3$ folds of that of mesoporous counterpart, and outperformed many other reported state-of-art CdS-based catalysts. A confinement effect of CdS NPs within UiO-66 cage could respond for its high activity, which could shorten the electron-transport distance of NPs-MOFs-reactant, and protect the active CdS NPs from photocorrosion. The finding here provides a straightforward paradigm and mechanism to rationally fabricate advance NPs/ MOFs for diverse applications.
\end{abstract}

(C) 2021, Dalian Institute of Chemical Physics, Chinese Academy of Sciences. Published by Elsevier B.V. All rights reserved.

\section{Introduction}

Thanks to their permanent porosity and appealing structures, metal organic frameworks (MOFs) have found diverse applications in gas adsorption [1], separation [2], drug delivery [3], catalysis [4], etc. Their large internal surface area offers an ideal platform for the stabilization of functional nanoparticles (NPs) [5], and the accommodated NPs on MOFs create additional active sites for the catalytic reactions [6-8]. Successful examples of such kind include Pd/UiO-66, Pt/MIL-101, Pt/ZiF-8, TiO 2 /ZIF-8, CdS/UiO-66( $\left.\mathrm{NH}_{2}\right), \mathrm{MoS}_{2} / \mathrm{PBA}$, etc. [9-13], all of which exploit the large surface area, rich active sites, and tunable cavities of MOFs [14,15]. Unfortunately, the pore size of MOFs normally restricted to microporous regime greatly ham- pers fabrication of advance NPs/ MOFs for diverse applications $[4,16]$.

Hierarchically porous MOFs have given rise to some advanced NPs/MOFs photocatalysts with gratifying performance thanks to the presence of larger pores, with mesopores of 2-50 $\mathrm{nm}$ and macropores of $>50 \mathrm{~nm}$ [16-19]. Establishing strategies to prepare hierarchically porous MOFs is indispensable for attaining high-performing NPs/MOFs, and include ligand extension, templating, and chemical etching, etc. [20-22]. These methods allow access to nanocage-like MOFs with a single large void as well as mesoporous MOFs with randomly distributed pores. To date, it remains a formidable challenge to tune the pore size of any given MOF spanning from mesopore to macrospore $[23,24]$. Owing to this limitation, how the pore size of

\footnotetext{
* Corresponding author. E-mail: zyzhuang@fzu.edu.cn

\# Corresponding author. E-mail: yuyan_1972@126.com

This work was supported by the National Natural Science Foundation of China (U1905215, 51772053, 51672046).

DOI: 10.1016/S1872-2067(20)63661-0 | http://www.sciencedirect.com/science/journal/18722067 | Chin. J. Catal., Vol. 42, No. 1, January 2021
} 
MOFs impacts the performance of NPs/MOFs remains elusive. In fact, prior studies have demonstrated: (1) The spatial distribution of NPs in the MOFs heavily affects the catalytic performance of NPs/MOFs [25,26]. For instance, strong correlation was found between the photocatalytic efficiency for hydrogen production and the location of Pt NPs relative to the UiO-66 $\left(\mathrm{NH}_{2}\right)$ where the NPs are hosted [27]. (2) Notice that established methods to manipulate the spatial relationship between NPs and MOFs commonly require tedious and time-consuming procedures such as pre-treatment of MOFs by solvent exchange, host activation, or surfactant-assisted surface modification [28], yet still do not offer the desired level of control. (3) Although the meso- and macro-pores of MOFs are both large enough to accommodate NPs within its framework $[29,30]$, elucidating the mechanism response of pore size to performance of NPs/MOFs is still imperative for controllable design of sophisticated catalysts.

UiO-66 is a Zr-based MOF with a face-centered cubic crystal structure that has good physicochemical stability and semiconductor properties [31,32]. UiO-66 crystals prepared from solution-based synthesis always have a stable and regular octahedral morphology. In a previous report, we etched solid UiO-66 crystal with $\mathrm{WO}_{4}{ }^{2-}$ to prepare macroporous UiO-66 nanocage of a single cavity at macroscale (500-700 nm) (Scheme 1) [18]. Recently, in a revised synthesis using 2-amino-terephthalic acid to replace the 1,4-benzenedicarboxylic acid ligand, our lab succeeded in creating mesoporous $\mathrm{UiO}-66\left(\mathrm{NH}_{2}\right)$ with a pore size of $2-20 \mathrm{~nm}$ (vide infra), and we noticed that the pore size heavily impacted the spatial distribution of NP within the fabricated UiO-66 $\left(\mathrm{NH}_{2}\right)$. The previous macroporous UiO-66 and this new mesoporous UiO-66 $\left(\mathrm{NH}_{2}\right)$ thus establish fair grounds for comparison and their difference allows us to evaluate the catalytic performance of the derived NPs/MOFs with regard to the distinct and highly controlled pore size.

In the past, catalytic reduction of 4-nitroaniline has been proved to be an effective process for the preparation of p-phenylenediamine (PDD), an important class of industrial intermediates for a variety of industrial chemicals [33]. Using $\mathrm{CdS}$ an indicator and an exploratory tool for catalyzing reduction of 4-nitroaniline, we deposited CdS both on the external surface of mesoporous $\mathrm{UiO}-66\left(\mathrm{NH}_{2}\right)$ and within the large cavity of the macroporous UiO-66 nanocage. Our result shows the rate

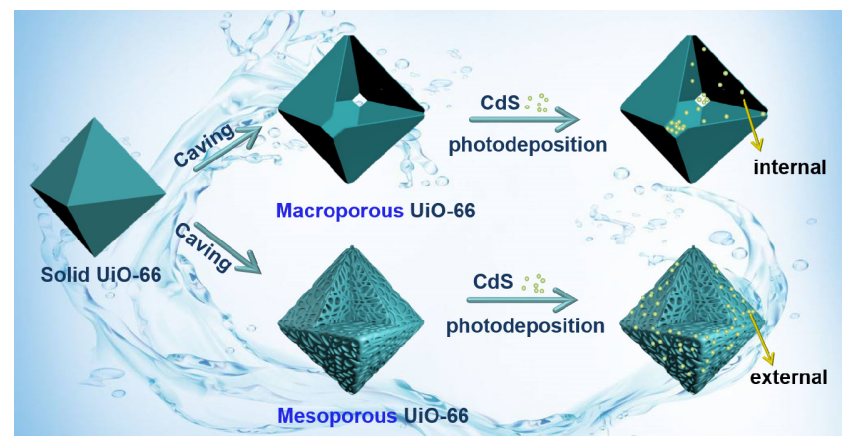

Scheme 1. Scheme illustrating the preparation of CdS/UiO-66 hybrids with distinct macro- and meso-pores following similar procedure. constant of NPs/UiO-66 normalized to NPs content followed in order of macroporous $>$ mesoporous $>$ solid counterparts. The macroporous CdS NPs/UiO-66 also outperformed many other CdS/MOF nanomaterials emerged in recent years, highlighting the superiority of macroporous MOFs-based nanocage on advanced catalysts design. The contributions of pore size to the light absorption, carrier generation and transfer, and NPs location were systemically investigated. The results demonstrated different distribution of NPs results in different activities and a confinement effect can be introduced to describe the high activity and durability of cage-based catalyst.

\section{Experimental}

\subsection{Materials}

Zirconium tetrachloride $\left(\mathrm{ZrCl}_{4}\right)$, 1,4-benzenedicarboxylic acid ( $\left.\mathrm{H}_{2} \mathrm{BDC}\right), 2$-aminoterephthalic acid $\left(\mathrm{H}_{2} \mathrm{BDC}-\mathrm{NH}_{2}\right), N$, $\mathrm{N}$-dimethylformamide (DMF), sodium tungstate $\left(\mathrm{Na}_{2} \mathrm{WO}_{4}\right)$, elemental sulfur $\left(\mathrm{S}_{8}\right)$, cadmium chloride $\left(\mathrm{CdCl}_{2} \cdot 2.5 \mathrm{H}_{2} \mathrm{O}\right)$, and methanol were purchased from Sinopharm Chemical Reagent Co., Ltd. All the reagents were of analytical grade and used as received without further purification. Ultrapure water used in the experiments was prepared by an ultrapure water purification system.

\subsection{Fabrication of macroporous UiO-66}

In a typical procedure, $\mathrm{ZrCl}_{4} \quad\left(\begin{array}{lll}0.18 & \mathrm{~g}\end{array}\right)$ and 1,4-benzenedicarboxylic acid ( $\mathrm{H}_{2} \mathrm{BDC}, 0.128 \mathrm{~g}$ ) were dissolved in $\mathrm{N}, \mathrm{N}$-dimethylformamide (DMF, $40 \mathrm{~mL}$ ) at room temperature. The mixture was stirred vigorously for $20 \mathrm{~min}$ to form a clear solution before the addition of acetic acid ( $5 \mathrm{~mL}$ ). The mixture was then stirred for another $10 \mathrm{~min}$, transferred into a $100 \mathrm{~mL}$ Teflon-lined stainless-steel autoclave, cooked at $120^{\circ} \mathrm{C}$ for $24 \mathrm{~h}$, and then cooled to room temperature. The precipitate was filtered and washed with DMF $(10 \mathrm{~mL} \times 3)$. The solids were then washed with methanol ( $10 \mathrm{~mL} \times 3)$, each time by firstly suspending the solids in methanol at room temperature for $24 \mathrm{~h}$ before centrifugation. The collected materials were finally dried at $100{ }^{\circ} \mathrm{C}$ under vacuum to give the bulk material, of which $0.1 \mathrm{~g}$ was added into the etching solution $(70 \mathrm{~mL})$. The etching solution was prepared as follows: $\mathrm{Na}_{2} \mathrm{WO}_{4}(8.25 \mathrm{~g})$ was firstly dissolved in deionized water $(25 \mathrm{~mL})$ under vigorous stirring at room temperature for $30 \mathrm{~min}$. The mixture was adjusted to $\mathrm{pH}=2.0$ by the dropwise addition of $\mathrm{HCl}(2 \mathrm{~mol} / \mathrm{L})$, then adjusted to $250 \mathrm{~mL}$ by adding deionized water, and finally adjusted to $\mathrm{pH}=2.3$ by adding oxalic acid to give a transparent solution. The etching solution containing bulk UiO-66 was sonicated for $10 \mathrm{~min}$, transferred into a $100 \mathrm{~mL}$ Teflon-lined stainless-steel autoclave, and cooked at $180{ }^{\circ} \mathrm{C}$ for $4 \mathrm{~h}$ before cooling to room temperature. The precipitate was collected, washed with deionized water for three times, and finally dried at $60^{\circ} \mathrm{C}$ under vacuum to give macroporous UiO-66 nanocages.

\subsection{Fabrication of mesoporous UiO-66( $\left.\mathrm{NH}_{2}\right)$}


$\mathrm{ZrCl}_{4}(0.2334 \mathrm{~g})$ and 2-aminoterephthalic acid $\left(\mathrm{H}_{2} \mathrm{BDC}-\mathrm{NH}_{2}\right.$, $0.128 \mathrm{~g}$ ) were dissolved in DMF ( $40 \mathrm{~mL})$ at room temperature. The mixture was stirred vigorously for $20 \mathrm{~min}$ to form a clear solution before the addition of acetic acid $(5 \mathrm{~mL})$. The mixture was then stirred for another $10 \mathrm{~min}$, transferred into a $100 \mathrm{~mL}$ Teflon-lined stainless-steel autoclave, cooked at $120^{\circ} \mathrm{C}$ for $24 \mathrm{~h}$, and then cooled to room temperature. The precipitate was filtered and washed with DMF $(10 \mathrm{~mL} \times 3)$. The solids were then washed with methanol $(10 \mathrm{~mL} \times 3)$, each time by firstly suspending the solids in methanol at room temperature for $24 \mathrm{~h}$ before centrifugation. The collected materials were finally dried at $100{ }^{\circ} \mathrm{C}$ under vacuum to give the bulk material, of which $0.1 \mathrm{~g}$ was added into the same etching solution $(70 \mathrm{~mL})$ as in Section 2.2. The etching solution containing bulk UiO-66 $\left(\mathrm{NH}_{2}\right)$ was sonicated for $10 \mathrm{~min}$, transferred into a 100 $\mathrm{mL}$ Teflon-lined stainless steel autoclave, and cooked at $180{ }^{\circ} \mathrm{C}$ for $4 \mathrm{~h}$ before cooling to room temperature. The precipitate was collected, washed with deionized water for three times, and finally dried at $60{ }^{\circ} \mathrm{C}$ under vacuum to give the mesoporous UiO-66 $\left(\mathrm{NH}_{2}\right)$.

\subsection{Deposition of CdS}

In a typical procedure, $\mathrm{CdCl}_{2} \cdot 2.5 \mathrm{H}_{2} \mathrm{O}(40 \mathrm{mg})$ and $\mathrm{S}_{8}(10 \mathrm{mg})$ were dispersed in ethanol ( $50 \mathrm{~mL})$ to form a stable suspension. The mixture was bubbled with $\mathrm{N}_{2}$ for 30 min in dark, after which UiO-66 or UiO-66( $\left.\mathrm{NH}_{2}\right)$ powder $(0.1 \mathrm{~g})$ was added to the suspension. The mixture was then irradiated with simulated solar light for $30 \mathrm{~min}$ by using a $300 \mathrm{~W}$ Xe arc lamp. The as-prepared samples were rinsed with deionized water and dried at $60^{\circ} \mathrm{C}$ under vacuum.

\subsection{Characterizations}

Crystal structures were determined by X-ray diffraction analysis on a PANalytical X'pert MPD X-ray diffractometer (XRD) with $\mathrm{Cu} K_{\alpha}$ radiation $(\lambda=1.5406 \AA)$ at $36 \mathrm{kV}$ and $30 \mathrm{~mA}$ in continuous scanning mode. The spectra were recorded over $2 \theta=5^{\circ}-60^{\circ}$ at $5^{\circ} / \mathrm{min}$ with a step size of $0.01^{\circ}$. The morphology of the samples was examined by scanning electron microscopy (SEM, Philips XL30) and transmission electron microscopy (TEM, FEI Tecnai G2 F20). N2 adsorption-desorption measurements were conducted on a Tristar II 3020 Specific Surface Area and Pore Size Analyzer at $77 \mathrm{~K}$ to examine the surface structure and pore distribution of all obtained materials. Fourier transform infrared (FTIR) spectra were recorded for all samples on a TJ270-30A infrared spectrophotometer (Tianjin, China). UV-vis diffuse reflectance spectroscopy (DRS) (Varian Cary 500 UV-vis spectrophotometer, Varian, USA) tests were carried out with an integrating sphere attachment ranging from 200 to $800 \mathrm{~nm}$ by using $\mathrm{BaSO}_{4}$ as a reflectance standard. Transient photocurrent measurements were performed on an electrochemical workstation (CHI-660C, Chenhua, China) with aqueous $\mathrm{Na}_{2} \mathrm{SO}_{4}(1 \mathrm{M})$ as the electrolyte solution. Electrochemical impedance spectroscopy (EIS) measurements were carried out at open circuit potential (OCP) under visible light irradiation $(\lambda>420 \mathrm{~nm})$ with aqueous $\mathrm{Na}_{2} \mathrm{SO}_{4}(0.1 \mathrm{M})$ as the electro- lyte soluion at a frequency range of $4 \times 10^{6}$ to $1 \times 10^{-2} \mathrm{~Hz}$.

\subsection{Photocatalytic reduction of 4-nitroaniline by CdS/UiO-66}

All procedures were operated under nitrogen atmosphere. The catalyst $(40 \mathrm{mg}$ ) and ammonium formate $(40 \mathrm{mg})$ were added into an aqueous solution of 4-nitroaniline $(20 \mathrm{mg} / \mathrm{L}, 40$ $\mathrm{mg}$ ). The mixture was then stirred for $30 \mathrm{~min}$ in dark to establish the adsorption-desorption equilibrium, then irradiated by the visible light $\left(20 \mathrm{~mW} / \mathrm{cm}^{2}\right)$ emitted from a $500 \mathrm{~W}$ Xe lamp equipped with a glass filter $(\lambda>420 \mathrm{~nm})$ to remove UV light. The concentration of the 4-nitroaniline during the photocatalytic reaction was monitored by colorimetry using a UV-vis spectrometer (UV-2100, Rayleigh Analytical Instrument Co. Ltd, China) at regular time intervals. The catalytic efficiency was calculated using the Lambert-Beer equation as follows

$$
\eta=\left(1-C_{t} / C_{0}\right) \times 100 \%
$$

where $\eta$ is the catalytic efficiency, $C_{0}$ is the initial 4-nitroaniline concentration, and $C_{t}$ is the 4-nitroaniline concentration at time $t$

\section{Results and discussion}

\subsection{Pore size engineering}

As depicted in Scheme 1, octahedral macroporous nanocages that contained a single macro-scale void were prepared by etching solid UiO-66 (Fig. S1) $\mathrm{WO}_{4}{ }^{2-}$ solution as previously reported [18] and are referred to as Mac-UiO (Fig. 1(a) and Figs. S2(a), (b)). Octahedral crystals with distinct mesopores (ca. 2-20 nm pore size) were prepared from UiO-66( $\left.\mathrm{NH}_{2}\right)$ with the identical etching procedure and are referred to as Mes-UiO(N) (Fig. 1(g) and Figs. S2(c), (d)).The difference of Mac-UiO and Mes-UiO(N) in pore size was validated by $\mathrm{N}_{2}$ gas absorption. With its 2-20 nm mesopores (inset picture of Fig. $1(\mathrm{l})$ ), Mes-UiO(N) gave a hysteresis loop in $\mathrm{N}_{2}$ uptake at moderate to high relative pressure (Fig. 1(1)) [34,35]. In contrast, such hysteresis loop was not observed for Mac-UiO (Fig. 1(f)). Because of the partial loss of micropores, the specific surface area of both Mac-UiO (472 $\mathrm{m}^{2} / \mathrm{g}$ ) and Mes-UiO(N) (155 m²/g) showed a decline compared with the corresponding solid counterpart (1129-1374 m²/g) (Fig. S3). The phase of caved UiO-66 remained unaltered according to XRD (Fig. S4(a)) and FTIR (Fig. S4(b)) [36]. Elemental mapping confirms the two etched sample has similar chemical component (Figs. 1(b), (h)), showing an incorporation of $\mathrm{W}$ in UiO-66 framework that simultaneous contribute to a red shift of light absorption of samples as discussed in the following (Fig. S5).

After fabricating Mac-UiO and Mes-UiO(N), CdS NPs were embedded via photo-induced deposition to prepare the corresponding heterostructures, denoted as Mac-Cd/UiO and Mes-Cd/UiO(N) respectively (Figs. 1(c), (i) and Fig. S6) [37]. Over the past decades, CdS is celebrated for its photocatalytic properties under visible light thanks to its narrow band gap $(\sim 2.4 \mathrm{eV})$ [38-46]. Control samples were also made by deposition of CdS NPs onto the solid counterparts (Fig. S7), to give $\mathrm{S}-\mathrm{Cd} / \mathrm{UiO}$ and S-Cd/UiO(N). For all substrates, the successful 

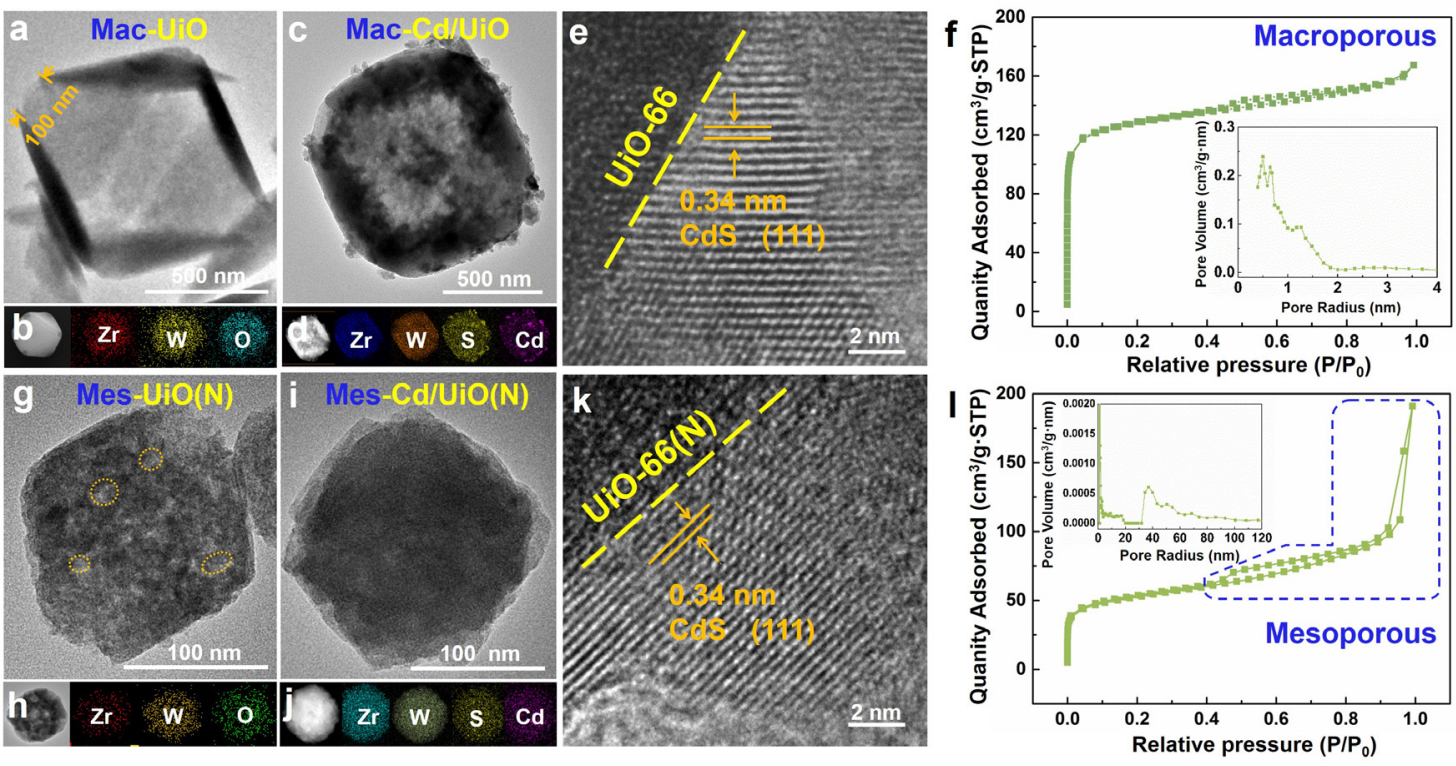

Fig. 1. TEM (a) and elemental mapping (b) of Mac-UiO; TEM (c), elemental mapping (d) and HRTEM (e) of Mac-Cd/UiO; $\mathrm{N}_{2}$ adsorption-desorption isotherms and pore size distribution of Mac-UiO (f); TEM (g) and elemental mapping (h) of Meso-UiO(N); TEM (i), elemental mapping (j) and HRTEM $(\mathrm{k})$ of Mes-Cd/UiO(N); $\mathrm{N}_{2}$ adsorption-desorption isotherms and pore size distribution of Mes-UiO(N) (l).

incorporation of CdS was confirmed by elemental mapping and EDX analysis (Figs. 1(d), (j) and Figs. S7(d), (h)), and the Cd content (used as an indicator of $\mathrm{CdS}$ content) ranged in $1.54-3.08 \mathrm{wt} \%$.

HRTEM images (Figs. 1(e), (k)) show that the deposited CdS were of similar grain size (4-6 nm) and identical phase, having a lattice spacing of $0.34 \mathrm{~nm}$ characteristic of the (111) planes of hexagonal CdS (JCPD NO. 65-3414) [47]. The structural integrity of UiO-66 and UiO-66( $\left.\mathrm{NH}_{2}\right)$ was also maintained after the deposition of CdS, as can be seem from the XRD (Fig. S8), SEM, and TEM results (Figs. 1(c), (i) and Fig. S7). There were no identifiable diffraction peaks of CdS can be detected in XRD, probably owing to the low content and small grain size of CdS. Chemical composition and elemental chemical states of $\mathrm{Cd} / \mathrm{UiO}$, Mac-Cd/UiO and Mes-Cd/UiO(N) were explored by X-ray photoelectron spectroscopy (XPS) (Fig. S9). Obviously, the peaks of $\mathrm{Zr}$ and $\mathrm{Cd}$ remained unchanged among all the samples, indicating the elemental chemical state of $\mathrm{Zr}$ ingredient was not altered after CdS coating. These observed structural similarity helps compare the performance of hybrids with regard to the content and location CdS as a result of MOF pore size.

\subsection{Pore-size dependent photocatalytic performance}

The photocatalytic activity of the heterostructures were evaluated with the photoreduction of 4-nitroaniline to amino compounds under visible light $(\lambda>420 \mathrm{~nm})$ irradiation (Fig. 2(a)). There was negligible catalytic activity from CdS-free Mac-UiO and Mes-UiO(N) (Fig. S10), and the reduction took place only when CdS was deposited on MOFs (Fig. 2(b)). For a quantitative comparison, the catalytic rate constant $(k)$ was then evaluated based on a linear fitting between $\ln \left(C_{t} / C_{0}\right)$ and time, where $C_{0}$ and $C_{t}$ represent the concentration of 4-nitroaniline at initial time and time $t$, respectively. Obviously, the $k$ of catalysts with macropores and mesopores were higher than that of solid counterparts (Fig. 2(c)), respectively. Specifically, the $k_{\text {Mac-Cd/Uio }}\left(0.234 \mathrm{~min}^{-1}\right)$ was 2.8 folds of $k_{\mathrm{S}-\mathrm{Cd} / \mathrm{UiO}}$ $\left(0.085 \mathrm{~min}^{-1}\right)$, while the $k_{\text {Mes-Cd/UiO(N) }}\left(0.046 \mathrm{~min}^{-1}\right)$ was 2.1 folds of of $k \mathrm{~s}$-Cd/Uio(N) $\left(0.021 \mathrm{~min}^{-1}\right)$.

The catalytic activity of the heterostructure depends on its CdS content (represented by Cd\%). A series of CdS/UiO-66 hybrids containing adjustable $\mathrm{CdS}$ content were prepared, including $1 / 2 \mathrm{Cd} / \mathrm{UiO}-66$ and $1 / 4 \mathrm{Cd} / \mathrm{UiO}-66$, wherein the $1 / n$ represents a reducing in CdS content shown in Table S1. The catalytic activity increased with rising CdS content (Figs. S11(a)-(d)). The catalytic performance was normalized based on CdS content using $k / \mathrm{Cd} \%$ as the corresponding benchmark (Fig. 2(d)), which ranked as follows: Mac-Cd/UiO (9.22 × 10-2 $\left.\mathrm{min}^{-1}\right)>$ Mes-Cd/UiO(N) $\left(2.99 \times 10^{-2} \mathrm{~min}^{-1}\right)>\mathrm{S}-\mathrm{Cd} / \mathrm{UiO}(2.42 \times$ $\left.10^{-2} \mathrm{~min}^{-1}\right)>\mathrm{S}-\mathrm{Cd} / \mathrm{UiO}(\mathrm{N})\left(0.69 \times 10^{-2} \mathrm{~min}^{-1}\right)$. The $\mathrm{k} / \mathrm{Cd} \%$ Mac-Cd/UiO was about 3-13 folds of that of mesoporous- and solid-counterparts. After consulting the literatures (Fig. 2(d) and Table S1), under unit amount of CdS, Mac-Cd/UiO also outperformed many other state-of-art CdS-based nanomaterials reported in recent years [33,48-54]. Such a result highlights that macroporous MOFs-based nanocage is superior in constructing of advanced catalysts.

\subsection{S-scheme photocatalytic mechanism}

It has been environed that the interconnected macro- or meso-pores of UiO-66 might take action through funneling the reactants into the active sites, enhancing the light absorption and/or booting the electron-hole separation [18,34,55]. According to the UV/Vis diffuse reflectance spectra (Fig. 2(e)), we found the samples after CdS loading all well inherited the feature of parent UiO-66 or UiO-66 $\left(\mathrm{NH}_{2}\right)$ and showed comparable light absorption ability with red shift to visible light region. 
a

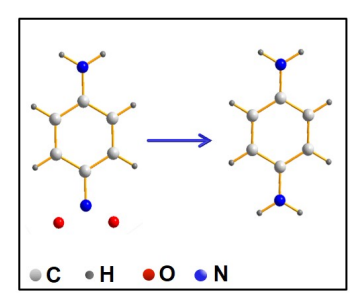

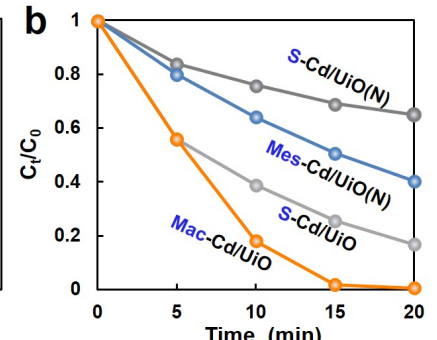
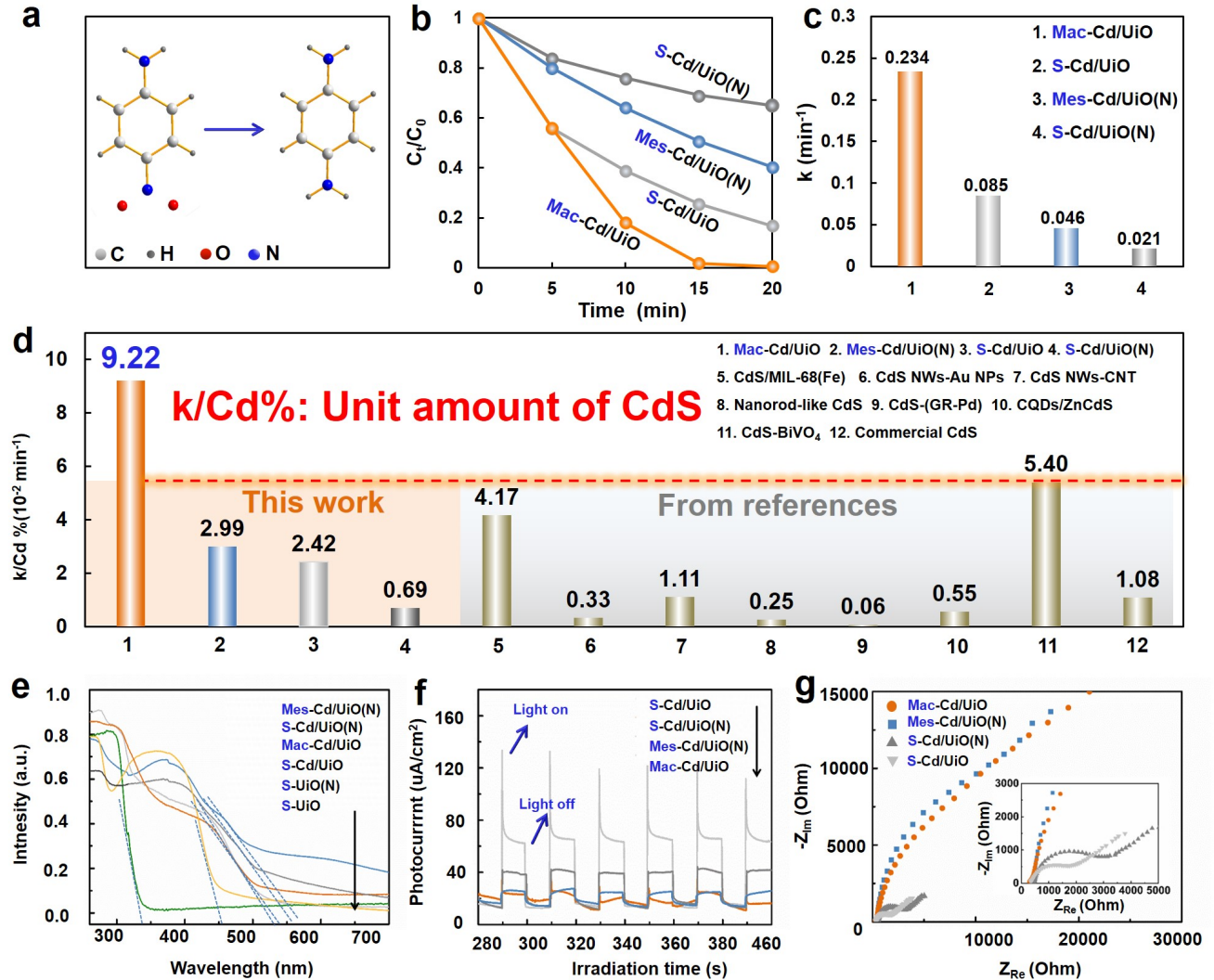

Fig. 2. The photocatalytic reduction of 4-nitroaniline (a); the photocatalytic efficiency (b) and corresponding rate constant (c) of 4-nitroaniline reduction with different catalysts (k); normalized catalytic performance with $k / \mathrm{Cd} \%$ as the benchmark (d); DRS of tested samples (e); TPR of tested samples (f); EIS curves of tested samples (g), the inset of (g) show the zoomed-in EIS for $Z_{R e}=0-50000 \mathrm{hm}$.

However, light absorption cannot be the determining step of photocatalyst in this work. As shown in Scheme 2, the band structure was further determined based on bandgap energy (Eg, Fig. S12(a)) analysis and Mott-Schottky curves (Fig. S12(b)). Accordingly, our results show the samples, despite having distinct activities, displayed similar energy structures.

As illustrated in Scheme 2, a step-scheme (S-scheme) heterojunction can be introduced to describe the charge transfer mechanism of between UiO-66 and CdS. As aforementioned, all the catalysts without $\mathrm{CdS}$ are inactive, indicating the photogenerated electrons on UiO-66 failed to reduce the 4-nitroaniline. Hence, as to the CdS/UiO-66, it must be the photo-generated electrons on the $\mathrm{CB}$ of $\mathrm{CdS}$ that responds for the 4-nitroaniline reduction. Also notice that the $\mathrm{CB}$ of $\mathrm{CdS}$ is more negative than the $\mathrm{CB}$ of UiO-66, and the electrons transfer from the $\mathrm{CB}$ of UiO-66 to CB of CdS is thermodynamically prohibited. Thus, it has been environed that S-scheme is more in electron-hole separation in which a high redox ability of photoinduced charge carriers can be maintained, when compared with traditional type-II heterojunction [56-59]. Following such principle, when Ui0-66 and CdS are in close contact, the electrons from CdS of a higher Fermi level will transfer to the UiO-66 of a lower Fermi level across their interface until their Fermi levels are equal. CdS losing electrons is positively charged and the UiO-66 getting electrons is negatively charged at the interface. Naturally, an internal electric field will be produced at the interface.
The band edge of CdS bends upward due to the loss of electrons, while band edge of UiO-66 bends downward due to the accumulation of electrons $[56,60]$. Under the visible light irradiation, the internal electric field can drive the recombination of the electrons on the CB of UiO-66 (of weak reductive ability) with the holes on the VB of CdS (of weak oxidative ability). The active photogenerated electrons in $\mathrm{CB}$ of $\mathrm{CdS}$ and holes in $\mathrm{VB}$ of UiO-66 are well preserved and separated in space, and attain a high redox capability of the heterojunction in photocatalysis process [61-63].

Our following analysis demonstrate the carries-transfer speed could not be the determining step of catalysis. As shown in Fig. 2(d), the Mac-Cd/UiO and Mes-Cd/UiO manifesting the higher activity, yet reflected a relatively lower transient photocurrent responses (TPR) (Fig. 2(f)) and larger electrochemical impedance spectroscopy (EIS) (Fig. 2(g)). Hence, more attentions were paid to $\mathrm{CdS}$ as shown in the following. Noticed that a photocurrent spike of S-Cd/UiO in TPR curves occurs at the initial time of irradiation, caused by the separation of photogenerated electron-hole pairs within the photo-electrode. Later, it decreases continuously with time and reaches a constant current. The decrease of the photocurrent can be descried by the holes accumulated at the CdS surface, competitively recombined with electrons from CdS conduction band, instead of being trapped or captured by reduced species in the electrolyte [64-66]. 


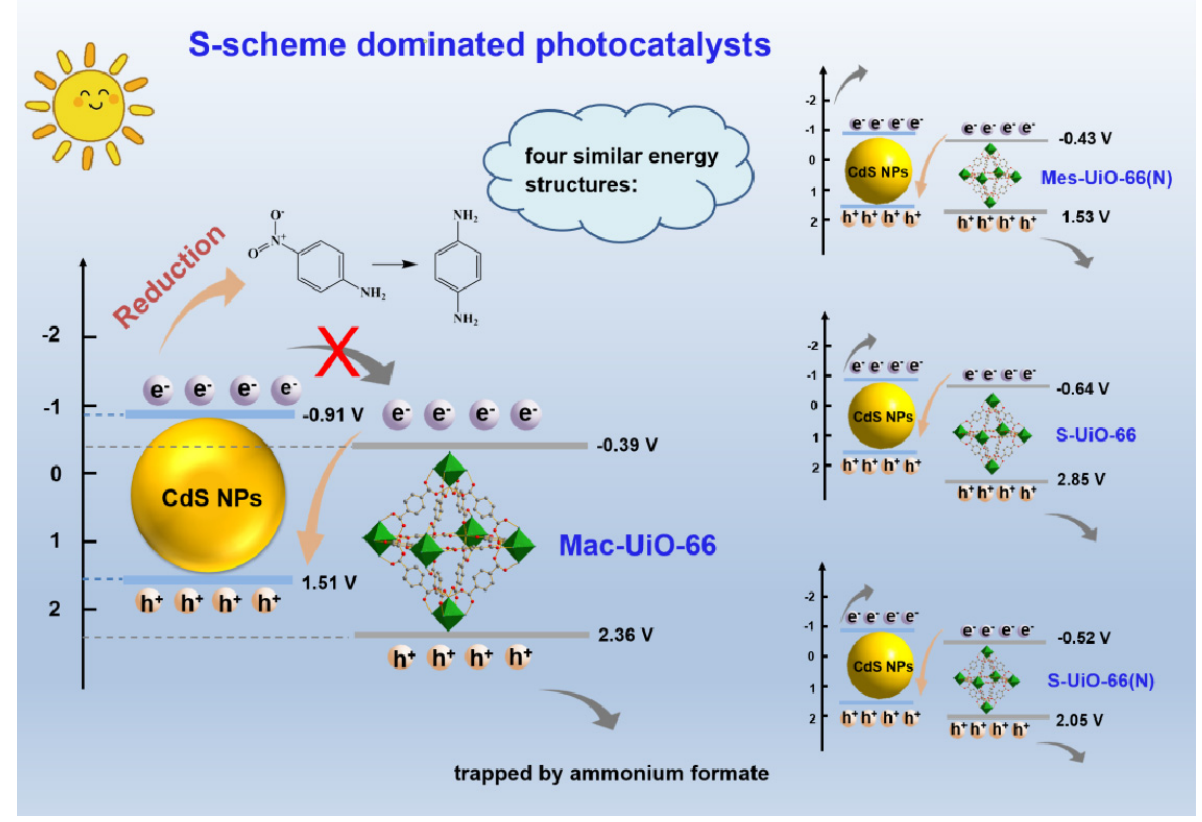

Scheme 2. Schematic illustration of the S-scheme dominated photocatalytic mechanism over CdS/UiO-66.

\subsection{Catalytic performance with respect to the location of NPs in} the MOF

Our following investigations indicate the pore size of UiO-66 impact the location of CdS, which determines the photoactivities. Lately, several works on NPs/MOFs start to realize the spatial distribution of NPs within MOFs framework could affect the activity [10], but no evidence show the pore-size dependent location of NPs in MOFs. To verity this, the spatial distribution of CdS within Mac-Cd/UiO was further examined by SEM, TEM, and linear EDS scans (Figs. 3(d)-(f)) compared with Mac-UiO (Figs. 3(a)-(c)). Notice that elemental mapping of Mac-Cd/UiO (Figs. 3(g)-(j)) revealed incorporation of CdS in $\mathrm{Zr}$ matrix. However, from a closer look at the SEM and TEM images (Figs. 3(d), (e) and Fig. S13), it can be noted that a substantial amount of CdS NPs attach preferentially onto the inner shell of Mac-Cd/UiO than on the external wall of the nanocage. The presence of CdS NPs within the nanocage is also found from some broken Mac-Cd/UiO particles (Fig. S14). According to linear EDS scanning, CdS tends to deposit onto the inner shell and near the opening of cavity of macroporous UiO-66 nanocage (Fig. 3(f)), probably because the inner surface is rough and has higher surface area for CdS deposition (Fig. S15). In fact, when twice amount of CdS NPs were intentionally introduced, the mass of CdS NPs still tended to deposit onto the inner shell of Mac-2Cd/UiO (Fig. S16(b)). In contrast, CdS NPs fully cover the MOF surface in S-Cd/UiO counterpart (Fig. $\mathrm{S} 16(\mathrm{a})$ ). As a result, the Mes-Cd/UiO(N) (Fig. S17) and $\mathrm{S}-\mathrm{Cd} / \mathrm{UiO}$ (Fig. S18) display distinct flat Cd scanning curves.

After consulting the literatures $[67,68]$, we propose that confinement of CdS NPs within the Mac-UiO via encapsulation could improve the catalytic efficiency by shortening the distance of electron transport between NPs and MOFs and bring- ing closer the catalyst and the substrate. In this way, the light absorption and speed of carrier transfer are not the rate-limiting factor of catalytic activity. Besides, the confinement effect also helps suppress the light-deactivation of CdS $[69,70]$, and improve the durability of the CdS-based catalyst $[71,72]$. Inspiringly, the Mac-Cd/UiO maintained a high activity, with only a small $13.5 \%$ loss of activity (Fig. 4(a)). Notice that the morphology and structure of retrieved Mac-Cd/UiO remain unchanged after 5 cycles (Fig. S19). Figure 4(b) shows $46.3 \%$ deactivation of mesoporous sample, mainly since CdS NPs mostly resided on the surface and only a part in the mesopores of MOF. However, as shown in Figs. 4(c) and (d), the catalytic efficiency of S-Cd/UiO and S-Cd/UiO(N) became deactivate and

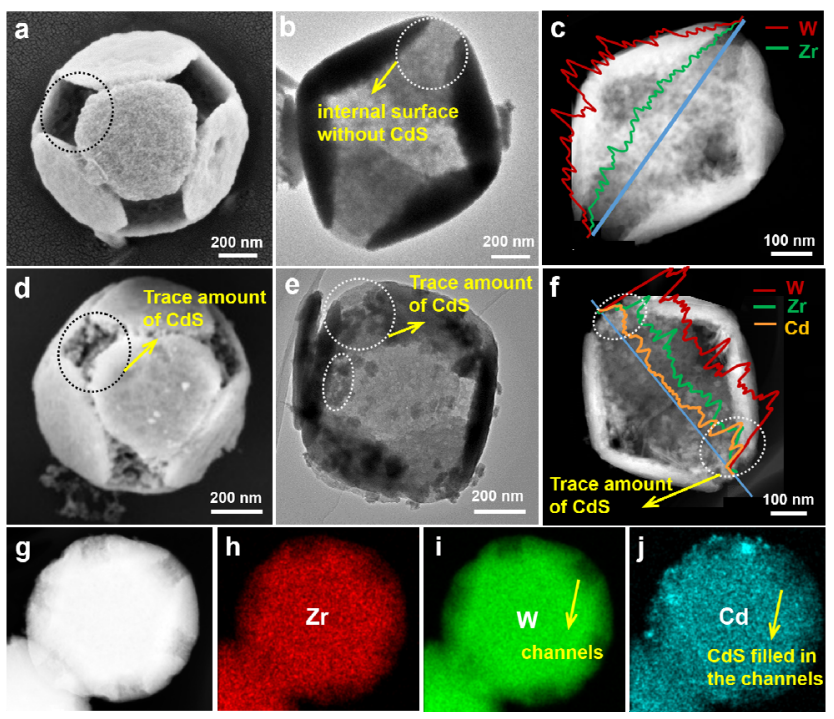

Fig. 3. SEM (a), TEM images (b), and Linear EDS results (c) of Mac-UiO; SEM (d), TEM images (e), and Linear EDS results (f) of Mac/Cd-UiO; Elemental mapping images of $\mathrm{Zr}, \mathrm{W}$ and $\mathrm{Cd}$ in a single crystal of $\mathrm{Mac} / \mathrm{Cd}-\mathrm{UiO}$ (g-j). 

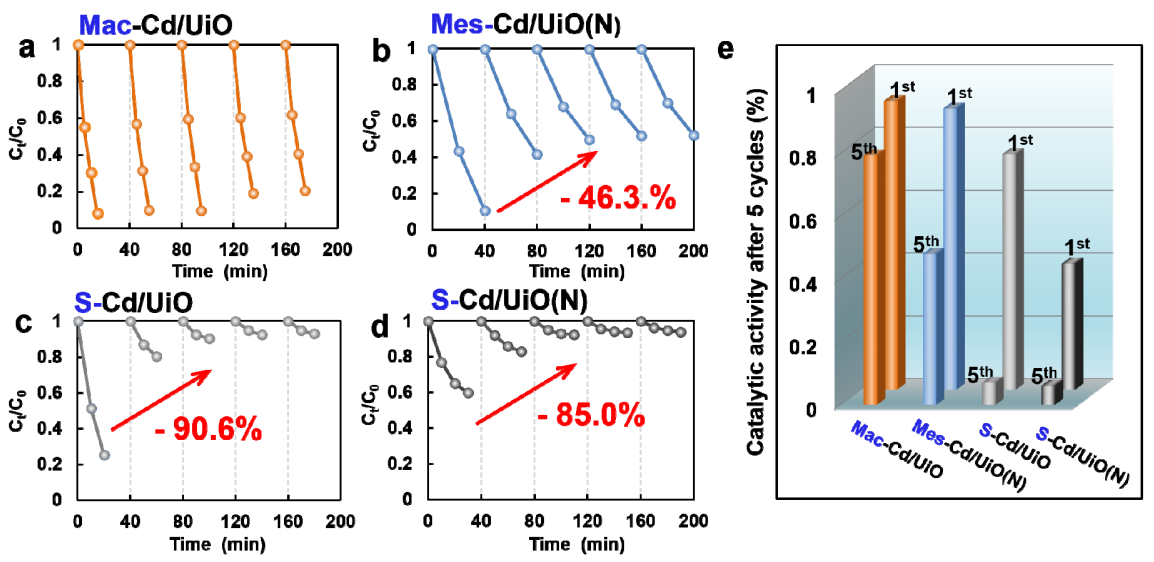

$\mathbf{f}$
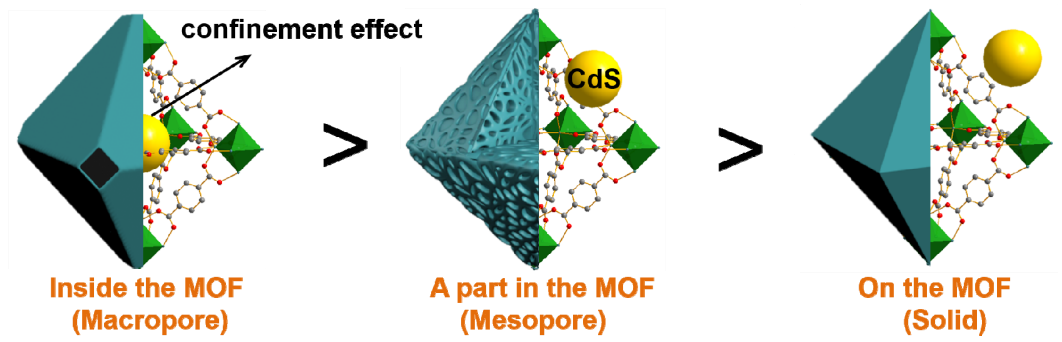

Fig. 4. Circulating experiments of Mac-Cd/UiO (a), Mes-Cd/UiO(N) (b), S-Cd/UiO (c) and S-Cd/UiO(N) (d), respectively; catalytic efficiency in $1^{\text {st }}$ cycle and after $5^{\text {th }}$ cycles of four samples (e); schematic diagram of macro-, meso-, solid samples with different CdS location (f).

the efficiency was cut down by $90.6 \%$ and $85.0 \%$. It is because the CdS NPs on the surface of MOF without protect can be easily be photocorroded and deactivated [73]. These observations further indicate that the present Mac-Cd/UiO nanocage with large cavity is able to provide a special confinement effect that benefits the activity and durability of the catalyst.

\section{Conclusions}

In conclusion, the presenting work revealed the performance of a CdS/UiO-66 hybrid was closely related to the spatial location of CdS NPs in UiO-66 framework. Specifically, the macroporous UiO-66 nanocages outperformed the mesoporous and solid counterparts to encapsulate $\mathrm{CdS}$ within its framework. Normalized to unit amount of CdS, the photocatalytic reaction constant of macroporous $\mathrm{CdS} / \mathrm{UiO}-66$ over 4-nitroaniline reduction was $\sim 3$ times that of the mesoporous counterpart, and supassed many reported state-of-art CdS-based catalysts given in literature. It highlights the promising use of MOFs-based nanocage for building advanced catalysts. Without surface modification, CdS NPs tended to deposit on external surface of mesoporous UiO-66, but spontaneously penetrated into the large cavity of macroporous UiO-66 nanocage. Subsequently, a confinement effect of $\mathrm{CdS}$ within UiO-66 cage shortened the electron-transport distance of NPs-MOFs-reactant, and protected encapsulated CdS from photocorrosion. The findings here shed lights on pore-size engineering of hierarchically porous MOFs, and unveil the mechanistic response of pore size to performances of NPs/MOFs for building superior catalysts.

\section{Conflict of Interest}

The authors declare no conflict of interest.

\section{References}

[1] K. Sumida, D. L. Rogow, J. A. Mason, T. M. McDonald, E. D. Bloch, Z. R. Herm, T. Bae, J. R. Long, Chem. Rev., 2012, 112, 724-781.

[2] J. R. Li, J. Sculley, H. C. Zhou, Chem. Rev., 2012, 112, 869-932.

[3] P. Horcajada, R. Gref, T. Baati, P.K. Allan, G. Maurin, P. Couvreur, G. Férey, R. E. Morris, C. Serre, Chem. Rev., 2012, 112, 1232-1268.

[4] Y. J. Lee, O. K. Farha, J. Roberts, K. A. Scheidt, S. B. T. Nguyen, J. T. Hupp, Chem. Soc. Rev., 2009, 38, 1450-1459.

[5] G. Lu, S. Li, Z. Guo, O.K. Farha, B.G. Hauser, X. Qi, Y. Wang, X. Wang, S. Han, X. Liu, J. S. DuChene, H. Zhang, Q. Zhang, X. Chen, J. Ma, S. C. J. Loo, W. D. Wei, Y. Yang, J. T. Hupp, F. Huo, Nat. Chem., 2012, 4, 310-316.

[6] K. Shen, L. Chen, J. Long, W. Zhong, Y. Li, ACS Catal., 2015, 5, 5264-5271.

[7] F. Meng, S. Zhang, L. Ma, W. Zhang, M. Li, T. Wu, H. Li, T. Zhang, X. Lu, F. Huo, J. Lu, Adv. Mater., 2018, 30, 1803263.

[8] H. Yang, S. J. Bradley, A. Chan, G. I. Waterhouse, T. Nann, P. E. Kruger, S. G. Telfer, J. Am. Chem. Soc., 2016, 138, 11872-11881.

[9] H. Liu, L. Chang, C. Bai, L. Chen, R. Luque, Y. Li, Angew. Chem. Int. Ed., 2016, 55, 5019-5023.

[10] K. Yuan, T. Song, D. Wang, X. Zhang, X. Gao, Y. Zou, H. Dong, Z. Tang, W. Hu, Angew. Chem. Int. Ed., 2018, 57, 5708-5713.

[11] A. Crake, K. C. Christoforidis, A. Gregg, B. Moss, A. Kafizas, C. Petit, Small, 2019, 15, 1805473.

[12] H. Zhao, X. Yang, R. Xu, J. Li, S. Gao, R. Cao, J. Mater. Chem. A, 2018, 6, 20152-20160. 


\section{Graphical Abstract}

Chin. J. Catal., 2021, 42: 78-86 doi: 10.1016/S1872-2067(20)63661-0

\section{Hierarchically porous S-scheme CdS/UiO-66 photocatalyst for} efficient 4-nitroaniline reduction

Jinxin Wei, Yawen Chen, Hongyang Zhang, Zanyong Zhuang *, Yan $\mathrm{Yu}^{*}$

Fuzhou University

Pore sizes of UiO-66 significantly affected the spatial location of CdS NPs incorporated and macroporous MOFs nanocage highlights its superiority on better advanced catalysts design.

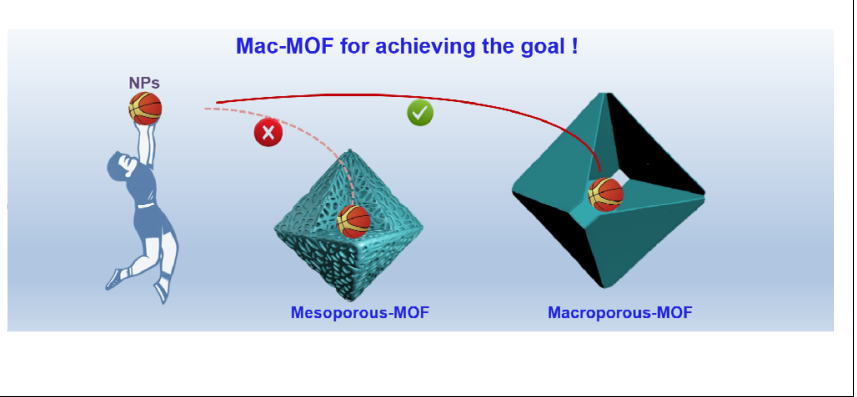

[13] X. Y. Yu, Y. Feng, Y. Jeon, B. Guan, X. W. Lou, U. Paik, Adv. Mater., 2016, 28, 9006-9011.

[14] P. Zhang, X. W. Lou, Adv. Mater., 2019, 31, 1900281.

[15] F. Dawei, W. Kecheng, S. Jie, L. Tian-Fu, P. Jihye, W. Zhangwen, B. Mathieu, Y. Andrey, Z. Xiaodong, Z. Hong-Cai, Angew.Chem. Int. Ed., 2015, 127, 151-156.

[16] G. Zhan, H. C. Zeng, Coord. Chem. Rev., 2016, 181-192.

[17] Y. Yue, P. F. Fulvio, S. Dai, Acc. Chem. Res., 2015, 48, 3044-3052.

[18] J. Wei, N. Cheng, Z. Liang, Y. Wu, Z. Zou, Z. Y. Zhuang, Y. Yu, J. Mater. Chem. A, 2018, 6, 23336-23344.

[19] Y. Wang, L. Li, P. Dai, L. Yan, L. Cao, X. Gu, X. Zhao, J. Mater. Chem. A, 2017, 5, 22372-22379.

[20] X. Xu, Z. Zhang, X. Wang, Adv. Mater., 2015, 27, 5365-5371.

[21] K. Jia, J. Ye, G. Zhuang, Z. Zhuang, Y. Yu, Small, 2019, 15, 1805478.

[22] K. Li, S. Lin, Y. Li, Q. Zhuang, J. Gu, Angew. Chem. Int. Ed., 2018, 57, 3439-3443.

[23] S. H. Lee, J. Kim, D. Y. Chung, J. M. Yoo, H. S. Lee, M. J. Kim, B. S. Mun, S. G. Kwon, Y. E. Sung, T. Hyeon, J. Am. Chem. Soc., 2019, 141, 2035-2045.

[24] K. Shen, L. Zhang, X. Chen, L. Liu, D. Zhang, Y. Han, J. Chen, J. Long, R. Luque, Y. Li, B. Chen, Science, 2018, 359, 206-210.

[25] J. D. Xiao, Q. Shang, Y. Xiong, Q. Zhang, Y. Luo, S. H. Yu, H. L. Jiang, Angew. Chem. Int. Ed., 2016, 55, 9389-9393.

[26] M. Zhao, K. Yuan, Y. Wang, G. Li, J. Guo, L. Gu, W. Hu, H. Zhao, Z. Tang, Nature, 2016, 539, 76-80.

[27] J. D. Xiao, Q. Shang, Y. Xiong, Q. Zhang, Y. Luo, S. H. Yu, H. L. Jiang, Angew. Chem. Int. Ed., 2016, 55, 9389-9393.

[28] L. Chen, X. Chen, H. Liu, C. Bai, Y. Li, J. Mater. Chem. A, 2015, 3, 15259-15264.

[29] H. Noh, C. W. Kung, T. Islamoglu, A. W. Peters, Y. Liao, P. Li, S. J. Garibay, X. Zhang, M. R. DeStefano, J. T. Hupp, O. K. Farha, Chem. Mater., 2018, 30, 2193-2197.

[30] L. Chen, B. Huang, X. Qiu, X. Wang, R. Luque, Y. Li, Chem. Sci., 2015, 7, 228-233.

[31] B. Liu, X. Liu, J. Liu, C. Feng, L. Zhu, C. Li, Y. Gong, L. Pan, S. Xu, C.Q. Sun, Appl. Catal. B, 2017, 226, 234-241.

[32] Y. Su, Z. Zhang, H. Liu, Y. Wang, Appl. Catal. B, 2017, 200, 448-457.

[33] W. Wu, G. Liu, Q. Xie, S. Liang, H. Zheng, R. Yuan, W. Su, L. Wu, Green Chem., 2012, 14, 1705-1709.

[34] W. Ying, L. Li, P. Dai, L. Yan, L. Cao, X. Gu, X. Zhao, J. Mater. Chem. A, 2017, 5 22372-22379.

[35] H. R. Abid, H. Tian, H. M. Ang, M.O. Tade, C. E. Buckley, S. Wang, Chem. Eng. J., 2012, 187, 415-420.

[36] Y. Y. Fu, C. X. Yang, X. P. Yan, Chem. Commun., 2013, 49,

7162-7164.

[37] K. Y. Jiang, X. C. Dai, Y. Yu, Q. L. Mo, F. X. Xiao, J. Phys. Chem. C, 2018, 122, 12291-12306.

[38] W. Zhong, S. Shen, M. He, D. Wang, Z. Wang, Z. Lin, W. Tu, J. Yu, Appl. Catal. B, 2019, 258, 117967.

[39] Z. Chen, C. Feng, W. Li, Z. Sun, J. Hou, X. Li, L. Xu, M. Sun, Y. Bu, Chin. J. Catal., 2018, 39, 841-848.

[40] Y. Xia, B. Cheng, J. Fan, J. Yu, G. Liu, Small, 2019, 15, 1902459.

[41] T. Di, B. Cheng, W. Ho, J. Yu, H. Tang, Appl. Surf. Sci., 2019, 470, 196-204.

[42] Q. Li, T. Shi, X. Li, K. Lv, M. Li, F. Liu, H. Li, M. Lei, Appl. Catal. B, 2018, 229, 8-14.

[43] F. Cheng, H. Yin, Q. Xiang, Appl. Surf. Sci., 2017, 391, 432-439.

[44] Z. W. Zhang, Q. H. Li, X. Q. Qiao, D. Hou, D.-S. Li, Chin. J. Catal., 2019, 40, 371-379.

[45] B. Ma, R. Zhang, K. Lin, H. Liu, X. Wang, W. Liu, H. Zhan, Chin. J. Catal., 2018, 39, 527-533.

[46] J. Low, B. Dai, T. Tong, C. Jiang, J. Yu, Adv. Mater., 2019, 31, 1802981.

[47] S. Wang, B. Zhu, M. Liu, L. Zhang, J. Yu, M. Zhou, Appl. Catal. B, 2019, 243, 19-26.

[48] R. Liang, F. Jing, G. Yan, L. Wu, Appl. Catal. B, 2017, 218, 452-459.

[49] B. Weng, S. Liu, N. Zhang, Z. R. Tang, Y. J. Xu, J. Catal., 2014, 309, 146-155.

[50] Y. Y. Chai, D. P. Qu, D. K. Ma, W. Chen, S. Huang, Appl. Surf. Sci,, 2018, 450, 1-8.

[51] S. Liu, Y. J. Xu, Nanoscale, 2013, 5, 9330-9339.

[52] C. Han, M. Q. Yang, N. Zhang, Y. J. Xu, J. Mater. Chem. A, 2014, 2, 19156-19166.

[53] W. Wu, R. Lin, L. Shen, R. Liang, R. Yuan, L. Wu, Phys. Chem. Chem. Phys., 2013, 15, 19422-19426.

[54] B. Han, S. Liu, Y. J. Xu, Z. R. Tang, RSC Adv., 2015, 5, 16476-16483.

[55] S. Wu, G. Zhuang, J. Wei, Z. Zhuang, Y. Yu, J. Mater. Chem. A, 2018, 6, 18234-18241.

[56] J. Fu, Q. Xu, J. Low, C. Jiang, J. Yu, Appl. Catal. B, 2019, 243, 556-565.

[57] P. Xia, S. Cao, B. Zhu, M. Liu, M. Shi, J. Yu, Y. Zhang, Angew. Chem. Int. Ed., 2020, 59, 5218-5225.

[58] H. Fan, H. Zhou, W. Li, S. Gu, G. Zhou, Appl. Surf. Sci., 2020, 504, 144351.

[59] J. Luo, Z. Lin, Y. Zhao, S. Jiang, S. Song, Chin. J. Catal., 2020, 41, 122-130.

[60] D. Xu, B. Cheng, W. Wang, C. Jiang, J. Yu, Appl. Catal. B, 2018, 231, 368-380. 
[61] H. Ge, F. Xu, B. Cheng, J. Yu, W. Ho, ChemCatChem, 2019, 11, 6301-6309.

[62] F. He, A. Meng, B. Cheng, W. Ho, J. Yu, Chin. J. Catal., 2020, 41, 9-20.

[63] R. Wang, J. Shen, W. Zhang, Q. Liu, M. Zhang, Zulfiqar, H. Tang, Ceram. Int., 2020, 46, 23-30.

[64] Q. Xiang, J. Yu, M. Jaroniec, J. Phys. Chem. C, 2011, 115, 7355-7363.

[65] Q. Xiang, J. Yu, M. Jaroniec, Nanoscale, 2011, 3, 3670-3678.

[66] Q. Li, H. Meng, J. Yu, W. Xiao, Y. Zheng, J. Wang, Chem. Eur. J., 2014, 20, 1176-1185

[67] J. Bao, J. He, Y. Zhang, Y. Yoneyama, N. Tsubaki, Angew. Chem. Int. Ed., 2008, 47, 353-356.
[68] P. Falcaro, R. Ricco, A. Yazdi, I. Imaz, S. Furukawa, D. Maspoch, R. Ameloot, J. D. Evans, C. J. Doonan, Coord. Chem. Rev., 2016, 307, 237-254.

[69] Z. Chen, Z. Guan, M. Li, Q. Yang, C. Li, Angew. Chem. Int. Ed., 2011, 50, 4913-4917.

[70] D. Wang, G. Yang, Q. Ma, M. Wu, Y. Tan, Y. Yoneyama, N. Tsubaki, ACS Catal., 2012, 2, 1958-1966.

[71] L. Shen, M. Luo, Y. Liu, R. Liang, F. Jing, W. Ling, Appl. Catal. B, 2015, 166, 445-453.

[72] X. Ning, W. Zhen, Y. Wu, G. Lu, Appl. Catal. B, 2018, 226, 373-383.

[73] I. B. Rufus, V. Ramakrishnan, B. Viswanathan, J. C. Kuriacose, $P$. Indian AS-Chem. Sci., 1989, 101, 487-497.

\title{
$\mathrm{S}$-型分级多孔CdS/UiO-66光催化剂的构建实现4-硝基苯胺的高效还原
}

\author{
魏晋欣 $^{\mathrm{a}, \mathrm{b}}$ ，陈雅文 ${ }^{\mathrm{a}, \mathrm{b}}$ ，张鸿洋 ${ }^{\mathrm{a}, \mathrm{b}}$ ，庄赞勇 ${ }^{\mathrm{a}, \mathrm{b}, *}$ ，于 岩 ${ }^{\mathrm{a}, \mathrm{b}, \text {, }}$ \\ a 福州大学新校区材料科学与工程学院, 福建福州 350108

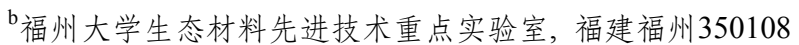

\begin{abstract}
摘要: 金属有机框架(MOFs)材料因其高孔隙率特性在气体吸附分离、药物传递、催化等领域具有广泛应用. 近年来, 将功 能化纳米颗粒(NPs)封装在MOFs 中的研究在催化领域引起了科学家的兴趣. 其中, 较大比表面积的MOFs 可以为NPs的分 散和固定提供理想的平台, 而NPs反过来可以为催化反应引入更多的活性位点, 提高催化效率. 然而, MOFs 本身的孔隙常 局限于微孔 $(<2 \mathrm{~nm})$, 这极大地限制了 NPs 在MOFs 孔隙中的有效封装. 因此, 设计并制备含有介孔 $(2-50 \mathrm{~nm})$ 或大孔(>50 $\mathrm{nm}$ )的多级孔MOFs, 揭示其孔径大小对复杂NPs/MOFs复合催化剂催化性能的影响具有重要意义. 然而, 具有不同孔径 MOFs的可控制备具有巨大挑战性, MOFs孔径如何影响和调控NPs/MOFs复合材料催化活性是一个悬而未决的科学问题.

本文结合金属离子刻蚀法和调控配体法设计了两种具有不同孔径(大孔和介孔)的UiO-66, 并系统研究了孔径大小对 CdS NPs的分布以及所形成的复合催化剂 $\mathrm{CdS} / \mathrm{UiO}-66$ 的催化性能的影响及机制. 我们首先阐明了UiO-66调控孔径后影响 和修饰CdS NPs的空间分布：对于具有开放大孔结构的UiO-66纳米笼, CdS NPs倾向于自发沉积在UiO-66纳米笼内壁上. 相比之下, CdS NPs则主要附着于介孔UiO-66的外表面. 据此, 具有大孔和介孔结构的CdS/UiO-66表现出不同的光催化性 能. 以光还原4-硝基苯胺反应为例, 大孔CdS/UiO-66的反应速率常数是介孔和实心样品的3-13倍, 且优于许多文献报道的 $\mathrm{CdS}$ 复合材料催化剂, 表明大孔结构在制备高效复合催化材料上的潜在优势. 通过光吸收能力、能级结构等计算表征, 该催 化剂的电子空穴对传输遵循S-型异质结光催化机制; 大孔CdS/UiO-66具有较高光催化活性可归因于纳米笼对NPs的限域 效应, 即 $\mathrm{CdS}$ 被限制在UiO-66纳米笼内, 缩短了催化剂与底物之间的电子传输距离; 空心纳米笼结构则保护其内部的 CdS NPs免受光腐蚀的影响, 进而获得较高的催化效率和循环稳定性. 可见, 本文提出了一种结合离子刻蚀法和调控配体法获 得具有不同孔径MOFs的有效策略, 阐明了调控MOFs的孔径尺寸可以影响NPs的空间分布, 是制约其性能的关键因素, 有 望为高效催化剂的设计及催化机制的研究提供新的依据.
\end{abstract}

关键词: 孔尺寸效应; 纳米限域; 多级孔金属有机框架材料; 纳米粒子/金属有机框架复合材料; 纳米笼

收稿日期: 2020-03-11. 接受日期: 2020-04-25. 出版日期: 2021-01-05.

*通讯联系人. 电子信箱: zyzhuang@fzu.edu.cn

\#通讯联系人. 电子信箱: yuyan_1972@126.com

基金来源：国家自然科学基金(U1905215, 51772053, 51672046).

本文的电子版全文由Elsevier出版社在ScienceDirect上出版(http://www.sciencedirect.com/science/journal/18722067). 